\title{
Diabetic Patients During and After COVID-19 Epidemic
}

\author{
Carretero-Anibarro Enrique* \\ Medicina Familiar y Comunitaria, Unidad de Gestión Clínica Estepa, Red de Grupos de Estudio de la Diabetes en Atención Primaria (redGDPS), Diabetes \\ Working Group Spanish Society of Family and Community Medicine Spain
}

Submission: April 14, 2020; Published: April 22, 2020

*Corresponding author: Carretero-Anibarro Enrique, Medicina Familiar y Comunitaria, Unidad de Gestión Clínica Estepa, Red de Grupos de Estudio de la Diabetes en Atención Primaria (redGDPS), Diabetes Working Group Spanish Society of Family and Community Medicine, Seville, Spain

\begin{abstract}
Since the beginning of the outbreak millions of confirmed cases of 2019 novel coronavirus disease (COVID-19) have been already reported from many countries worldwide. Many developed countries such as Spain and other European countries now ranks the most affected by the epidemic in the world in total number of cases. Measures made to protect citizens during the coronavirus pandemic are disrupting the health system and would mean that other patients affected by chronic diseases could be mismanaged and suffer complications. There have been reports of significant shortages of medical staff and medical equipment dedicated to diabetic patients that have been moved to other saturated areas. Here is our chance to start a complete redesign of almost all the healthcare delivery systems and processes. This pandemic could be seen as a great opportunity to remind health care providers and managers as well, that patients are the keystone.
\end{abstract}

Keywords: Coronavirus; Epidemic; Diabetic patients; Healthcare systems

Abbreviations: COVID-19: Coronavirus 2019; DM: Diabetes Mellitus; HbA1c: Glycated Hemoglobin

\section{Introduction}

Since the beginning of the outbreak millions of confirmed cases of 2019 novel coronavirus disease (COVID-19) have been already reported from many countries worldwide [1]. Many more persons would be infected in the following months. The case detection rate is changing daily and can be tracked in almost real time on different website provided by the Center for Systems Science and Engineering at Johns Hopkins University [2], European Centre for Disease Prevention and Control [3] and other forums.

As the applied case definitions and testing strategies in the affected areas could differ the data are not directly comparable [3]. This data show us that many developed countries such as Spain and other European countries now ranks the most affected by the epidemic in the world in total number of cases. In fact, Spain is one of the countries that has shouldered the heaviest burden in tackling this grim epidemic [4].

In Spain, hospitals and healthcare centers in primary care have been overwhelmed by coronavirus patients4. Although Spain does have universal health care and all citizens (Spanish and foreigners) are beneficiaries of public health services. Due to austerity measures made during the 2008-2014 Spanish financial crisis the capacity of the healthcare system was reduced dramatically [5]. The health system is chronically understaffed and suffers an acute lack of adequate resources, supplies and equipment which has led to high infection rates especially among health providers and those who live in nursing homes [5].

The virus, spread globally, has caused an enormous impact on health systems and economies. Countries all around the world have been forced to confront the crisis and health systems have been sorely tested [6]. Swift and decisive actions have been taken to mitigate the development of a full-blown pandemic [7]. Measures made to protect citizens during the coronavirus pandemic are disrupting the health system and would mean that other patients affected by chronic diseases could be mismanaged and suffer complications [8]. There have been reports of significant shortages of medical staff and medical equipment dedicated to diabetic patients that have been moved to other saturated areas [9]. Lack of clinicians and basic healthcare units are key roadblock to handle and treat diabetic patients [10].

The nationwide lockdown designed to stop the spread of the COVID-19 is having a dramatic impact on diabetic patients as the following examples show [11]:

a) Restrictions on movement means that patients are unable to do physical activity. It is likely that prolonged home stay may lead to increased sedentary behaviors and reducing activity. 


\section{Current Research in Diabetes \& Obesity Journal}

b) Eating healthy foods would be much more difficult for people with economic problems, food cravings and addictions or other unhealthy habits, even if there are enough food supplies to maintain a healthy diet.

c) Regular diabetes screening checks such as: blood pressure, blood glucose levels including HbA1c, cholesterol and triglycerides, kidney function, eyes and feet have been limited during the lockdown and when it will be stopped many complications may have evolved and produce severe damage.

d) The hidden damage of confinement: the psychological effects. The mental health consequences should not be ignored or minimized, isolation can lead to stress, anxiety and depression. Isolation persistent effects on people's minds and behavior can affect their blood glucose levels and how they manage their diabetes in general. Over time, this would affect diabetic patient's health.

These data suggested that the COVID-19 patients with diabetes are at higher risk of excessive uncontrolled glycemic control, which may contribute to a poorer prognosis of these patients [12]. As a result of these and other changes the risk of most diabetes-related complications could be higher [13]. Furthermore, the second part is still to come, how this crisis will shape the care given to these patients. Now most developed countries offer people all the healthcare they need. This safe net could be disrupted or broken [14]. But in the midst of all this harsh scenario there are also good news that encourage us to keep on working. On the positive side, many of our patients and clinicians have adapted to this new and unpredictable scenario with creative problem solving [13].

Here is our chance to start a complete redesign of almost all the healthcare delivery systems and processes. This could be a turning point to focusing our efforts on quality, self-management and patient safety rather than improving access to services and achieving targets for patients' waiting times [15]. This pandemic could be seen as a great opportunity to remind health care providers and managers as well, that patients are the keystone. The patient should be put more at the center of healthcare provision. It compels us strengthen every means to of empowering our patients. Empowering the patients by giving the knowledge, improving their skills, encouraging patient participation, making them an active participant and enabling them to overcome their daily trials [16]. This means better teaching methods, emphasizing the promotion of self -management, implementing of the objectives agreed in common.

All these measures may lead to a more useful longer-tend outcomes, helping the patients to attain glycemic control and reduces the risk of complications in people with diabetes. The responsibility for promoting and supporting these measures is shared by patients, clinicians and the health system. Under this perspective, a change of route in diabetes care is undoubtedly required, empowerment, is a path to be followed in pursuit of new more sustainable solutions and alternatives than the existing ones. As a final thought the above assessment is just a personal opinion on this matter. I am aware that not everyone will agree. Many colleagues may share my point of view and others may disagree with these positions. If there are dissenting opinions, there can be more than one, diversity and differences of opinion should be respectfully consider.

\section{Conclusion}

The patient should be put more at the center of healthcare provision. It compels us strengthen every means to of empowering our patients. Empowering the patients by giving the knowledge, improving their skills, encouraging patient participation, making them an active participant and enabling them to overcome their daily trials16. All these measures may lead to a more useful longertend outcomes, helping the patients to attain glycemic control and reduces the risk of complications in people with diabetes. The responsibility for promoting and supporting these measures is shared by patients, clinicians and the health system.

\section{References}

1. Xiaoyi Huang, Fengxiang Wei, Liang Hu (2020) Epidemiology and Clinical Characteristics of COVID-19. Arch Iran Med 23(4): 268-271.

2. https://gisanddata.maps.arcgis.com/apps/opsdashboard/index. html\#/bda7594740fd40299423467b48e9ecf6.

3. https://www.ecdc.europa.eu/en/covid-19-pandemic.

4. World Health Organization (2000) Health Care Systems in Transition: Spain. p. 43.

5. Spijker J, Gumà J (2018) Positive or negative for population health? Responses to the debate regarding the two sides of how an economic crisis affects health based on the Spanish case. Salud Colect 14(4): 689693.

6. Karnon J (2020) A Simple Decision Analysis of a Mandatory Lockdown Response to the COVID-19 Pandemic. Appl Health Econ Health Policy.

7. Yen MY, Schwartz J, Chen SY (2020) Interrupting COVID-19 transmission by implementing enhanced traffic control bundling: Implications for global prevention and control efforts. J Microbiol Immunol Infect (20): 30071-30072.

8. Hartley DM, Perencevich EN (2020) Public Health Interventions for COVID-19: Emerging Evidence and Implications for an Evolving Public Health Crisis. JAMA.

9. Gupta R, Ghosh A, Singh AK, Misra A (2020) Clinical considerations for patients with diabetes in times of COVID-19 epidemic. Diabetes Metab Syndr 14(3): 211-212.

10. Bloomgarden ZT (2020) Diabetes and COVID-19. J Diabetes 12(4): 347-348.

11. Yang JK, Feng Y, Yuan MY, Yuan SY, Fu HJ (2020). Plasma glucose levels and diabetes are independent predictors for mortality and morbidity in patients with SARS. Diabet Med 23(6): 623-628.

12. Amit Akirov, Alon Grossman, Tzipora Shochat, Ilan Shimon (2017) Mortality Among Hospitalized Patients with Hypoglycemia: Insulin Related and Noninsulin Related. J Clin Endocrinol Metab 102(2): 416424. 


\section{Current Research in Diabetes \& Obesity Journal}

13. Aihong Wang, Weibo Zhao, Zhangrong Xu, Jianwen Gu (2020) Timely blood glucose management for the outbreakof 2019 novel coronavirus disease (COVID-19) urgently needed. Diabetes Res Clin Pract 162 108118.

14. Villabona CV (2020) Commentary: COVID-19 and diabetes. Diabetes Res Clin Pract 6: 108138.
15. Derek Bell (2006) Improving health care through redesign. It's time to shift from small projects to whole systems. BMJ 332(7553): 12861287.

16. Beres LK, Simbeza S, Holmes CB, Mwamba C, Mukamba N (2019) Human-Centered Design Lessons for Implementation Science: Improving the Implementation of a Patient-Centered Care Intervention. J Acquir Immune Defic Syndr 82(Suppl 3): 230-243.

Your next submission with Juniper Publishers
will reach you the below assets
- Quality Editorial service
- Swift Peer Review
- Reprints availability
- E-prints Service
- Manuscript Podcast for convenient understanding
- Global attainment for your research
- Manuscript accessibility in different formats
( Pdf, E-pub, Full Text, Audio)
- Unceasing customer service
Track the below URL for one-step submission
https://juniperpublishers.com/online-submission.php

